\title{
The effect of cigarette smoking on flexibility in Japanese
}

\author{
Kanae Oda $^{1^{*}}$, Nobuyuki Miyatake ${ }^{1}$, Noriko Sakano $^{1}$, Takeshi Saito ${ }^{1,2}$, Akihiko Katayama $^{1}$, \\ Kenji Nishii ${ }^{3}$, Takeyuki Numata ${ }^{2}$ \\ ${ }^{1}$ Department of Hygiene, Faculty of Medicine, Kagawa University, Kagawa, Japan; \\ *Corresponding Author: oda@med.kagawa-u.ac.jp \\ ${ }^{2}$ Okayama Southern Institute of Health, Okayama Health Foundation, Okayama, Japan \\ ${ }^{3}$ Okayama Health Foundation Hospital, Okayama, Japan
}

Received 19 July 2012; revised 18 August 2012; accepted 31 August 2012

\begin{abstract}
To investigate the link between cigarette smoking and flexibility in the Japanese population, we used data of 4234 men and 9169 women, aged 20 - 79 years, in this cross-sectional investigation study. Flexibility such as sit and reach were measured. In addition, habits of cigarette smoking and exercise were obtained by well-trained medical staff. The effect of cigarette smoking on flexibility was evaluated. A total of 1613 men (38.1\%) and 995 women (10.9\%) were having habits of cigarette smoking. Flexibility in men was decreased with aging and that in women increased with aging under 60's. Flexibility in subjects with cigarette smoking was significantly lower than that in subjects without cigarette smoking even after adjusting for age and exercise habits in both sexes. Cigarette smoking might be modifiable factor of flexibility in the Japanese.
\end{abstract}

Keywords: Cigarette Smoking; Flexibility; Exercise Habits

\section{INTRODUCTION}

Cigarette smoking is a public health problem, and it has been reported that $32.2 \%$ in men and $8.4 \%$ in women are current smokers in Japan [1]. Cigarette smoking has also reported to be a strong risk factor for atherosclerosis and cardiovascular disease in a dose-dependent manner [2].

In 2006 in Japan, levels of maximal oxygen uptake and muscle strength were recommended as exercise and physical activity reference quantity for health promotion 2006 (EPARQ2006) by the Ministry of Health, Labor and Welfare, Japan [3] However, optimal value of the flexibility was not recommended [3] and the link be- tween cigarette smoking and flexibility in a large sample of Japanese has not yet been fully discussed.

Therefore, in this study, we evaluated the effect of cigarette smoking on flexibility in the Japanese.

\section{SUBJECTS AND METHODS}

\subsection{Subjects}

We used data of 4234 men ( $43.3 \pm 13.9$ years) and 9169 women (42.4 \pm 13.9 years) in a cross-sectional study. Subjects met the following criteria (Table 1): 1) they underwent an annual health check-up from June 1999 to November 2009 at Okayama Southern Institute of Health; 2) they had flexibility, exercise habits and cigarette smoking evaluated as part of their annual health check-up; and 3) all subjects provided written informed consent for the use of their data in the study.

Ethical approval for the study was obtained from the Ethical Committee of Okayama Health Foundation.

\subsection{Anthropometric Measurements}

The anthropometric parameters were evaluated by using the following respective parameters such as height, body weight, body mass index (BMI), abdominal circumference and hip circumference. BMI was calculated by weight/[height $]^{2}\left(\mathrm{~kg} / \mathrm{m}^{2}\right)$. The abdominal circumference was measured at the umbilical level and the hip was measured at the widest circumference over the trochanter in standing subjects after normal expiration [4].

\subsection{Cigarette Smoking}

The data on cigarette smoking was obtained at interviews by well-trained staff in a structured way. The subjects were asked if they currently smoked cigarettes. When the answer was "yes", they were classified as current smokers. When the answer was "no", they were classified as non-smokers. 


\subsection{Flexibility}

The flexibility of all the participants was measured as follows. Sit-and-reach measurements were obtained to assess the overall flexibility in the forward flexion, with the measurements recorded as the distance (in centimeters) between the fingertips and toes. The subject's knees were kept straight throughout the test and ankles were maintained at 90 degrees by having the soles of the feet pressed against a board perpendicular to the sitting surface [5].

\subsection{Exercise Habits}

The data on exercise habits were obtained at interviews conducted by well-trained staff using the structured method of the National Nutrition Survey in Japan. The subjects were asked if they currently exercise (over 30 min per session, 2 times per week for duration of 3 months). When the answer was "yes", they were classified as subjects with exercise habits. When the answer was "no", they were classified as subjects without exercise habits.

\subsection{Statistical Analysis}

Data are expressed as means \pm standard deviation (SD) values. A comparison of parameters was made using the unpaired $t$-test, $\chi^{2}$ test, one-factor ANOVA, Sheffes' $\mathrm{F}$ test, covariance analysis and logistic regression analysis; where $p<0.05$ was considered to indicate statistical significance.

\section{RESULTS}

Clinical profiles of enrolled subjects were summarized in Table 1. Flexibility was $2.9 \pm 10.1 \mathrm{~cm}$ in men and $9.5 \pm$ $8.9 \mathrm{~cm}$ in women. A total of 1613 men (38.1\%) and 995 women $(10.9 \%)$ were having habits of cigarette smoking (Table 2) and the prevalence of subjects with cigarette smoking decreased with aging.

Changes in flexibility as classified by age groups were evaluated. In men, flexibility was significantly decreased with aging. However, flexibility was significantly increased with aging under 60's in women (Table 3). In addition, it is well known that exercise habits were closely associated with cigarette smoking [6]. Therefore, we evaluated the relationship between cigarette smoking and exercise habits (Table 4). Significant relationship between cigarette smoking and exercise habits was noted in both sexes.

Finally, we compared flexibility between subjects with and without cigarette smoking (Table 5). Flexibility in subjects with cigarette smoking was significantly lower than that in subjects without cigarette smoking. The differences were remained even after adjusting for age and exercise habits.

Table 1. Clinical profiles of enrolled subjects.

\begin{tabular}{lcccccc}
\hline & \multicolumn{3}{c}{ Men } & & \multicolumn{2}{c}{ Women } \\
\cline { 2 - 6 } & Mean \pm SD & Minimum & Maximum & Mean \pm SD & Minimum & Maximum \\
\hline Number of subjects & 4234 & & & 9169 & \\
Age & $43.3 \pm 13.9$ & 20 & 79 & $42.4 \pm 13.9$ & 20 & 79 \\
Height $(\mathrm{cm})$ & $169.0 \pm 6.2$ & 145.3 & 190.9 & $156.3 \pm 5.7$ & 134.3 & 179.3 \\
Body weight $(\mathrm{kg})$ & $70.4 \pm 11.7$ & 39.1 & 175.7 & $55.1 \pm 9.0$ & 32.1 & 116.9 \\
Body mass index $\left(\mathrm{kg} / \mathrm{m}^{2}\right)$ & $24.6 \pm 3.6$ & 13.6 & 61.5 & $22.6 \pm 3.6$ & 12.9 & 48.7 \\
Abdominal circumference $(\mathrm{cm})$ & $84.3 \pm 10.2$ & 58.0 & 157.0 & $72.1 \pm 9.6$ & 43.3 & 123.6 \\
Hip circumference $(\mathrm{cm})$ & $94.2 \pm 6.3$ & 71.0 & 145.5 & $91.0 \pm 6.0$ & 58.5 & 132.0 \\
Flexibility $(\mathrm{cm})$ & $2.9 \pm 10.1$ & -38.0 & 33.6 & $9.5 \pm 8.9$ & -35.5 & 35.8 \\
\hline
\end{tabular}

Table 2. Prevalence of subjects with cigarette smoking.

\begin{tabular}{ccccc}
\hline & \multicolumn{2}{c}{ Men } & \multicolumn{2}{c}{ Women } \\
\cline { 2 - 5 } & Number of subjects & $\%$ & Number of subjects & $\%$ \\
\hline $20-29$ & 379 & 44.4 & 388 & 17.2 \\
$30-39$ & 434 & 42.3 & 269 & 13.6 \\
$40-49$ & 375 & 41.8 & 202 & 10.8 \\
$50-59$ & 390 & 36.8 & 103 & 5.7 \\
$60-69$ & 113 & 20.9 & 32 & 3.0 \\
$70-79$ & 22 & 16.8 & 1 & 0.5 \\
Total & 1613 & 38.1 & 995 & 10.9 \\
\hline
\end{tabular}


Table 3. Changes in flexibility as classified by age groups.

\begin{tabular}{|c|c|c|c|c|}
\hline & Men & & Women & \\
\hline & Mean \pm SD & $p$ & Mean \pm SD & $p$ \\
\hline $20-29$ & $4.9 \pm 9.9$ & & $8.0 \pm 9.6$ & \\
\hline $30-39$ & $3.3 \pm 10.3$ & $\mathrm{a}$ & $9.2 \pm 9.0$ & $\mathrm{a}$ \\
\hline $40-49$ & $3.3 \pm 9.9$ & $\mathrm{a}$ & $9.8 \pm 8.6$ & $\mathrm{a}$ \\
\hline $50-59$ & $1.8 \pm 9.7$ & $\mathrm{a}$ & $10.3 \pm 8.5$ & $a b$ \\
\hline $60-69$ & $1.0 \pm 9.7$ & $\mathrm{abc}$ & $11.3 \pm 8.0$ & $a b c$ \\
\hline $70-79$ & $-1.4 \pm 11.7$ & abcd & $9.9 \pm 8.4$ & \\
\hline
\end{tabular}

Table 4. Relationship between cigarette smoking and exercise habits.

\begin{tabular}{cccc}
\hline & Exercise habits $(+)$ & Exercise habits (-) & $p$ \\
\hline Men & 424 & & \\
Cigarette smoking (+) & 1056 & 1189 & $<\mathbf{0 . 0 0 0 1}$ \\
Cigarette smoking (-) & & 1565 & \\
Women & 147 & 848 & $<\mathbf{0 . 0 0 0 1}$ \\
Cigarette smoking (+) & 2279 & 5895 & \\
Cigarette smoking $(-)$ & &
\end{tabular}

Table 5. Comparison of flexibility between subjects with and without cigarette smoking.

\begin{tabular}{|c|c|c|c|c|c|}
\hline & Number of subjects & Mean \pm SD & $p$ & $p$ (After adjusting for age) & $\begin{array}{c}p \text { (After adjusting for age, } \\
\text { exercise habits) }\end{array}$ \\
\hline Men & & & \multirow{4}{*}{0.0002} & \multirow{4}{*}{0.0500} & \multirow{4}{*}{$<0.0001$} \\
\hline Cigarette smoking $(+)$ & 1613 & $2.2 \pm 10.2$ & & & \\
\hline Cigarette smoking (-) & 2621 & $3.3 \pm 10.0$ & & & \\
\hline Women & & & & & \\
\hline Cigarette smoking $(+)$ & 995 & $7.9 \pm 9.8$ & \multirow[b]{2}{*}{$<0.0001$} & \multirow[b]{2}{*}{0.0342} & \multirow[b]{2}{*}{$<0.0001$} \\
\hline Cigarette smoking (-) & 8174 & $9.7 \pm 8.8$ & & & \\
\hline
\end{tabular}

\section{DISCUSSION}

The main finding of this study is that cigarette smoking was might be modifiable factor of flexibility in the Japanese population.

In some literatures, the relationship between cigarette smoking and flexibility has been showed [7-9]. Conway has reported that they examined 1357 Navy men and fitness was negatively associated with cigarette smoking [7]. Boyce et al. also showed that smokers had signifycantly lower fitness scores in sit and reach flexibility in 514 police officers [8]. However, Ricci et al. reported that there were significant differences for age and flexibility in relation to the history of smoking i.e. ex-smoking women were shown to be younger and be more flexible than those who had never smoked [9]. They did not adjust for age when they compare flexibility between subjects with and without cigarette smoking. In this study, we solely evaluated the relationship between cigarette smoking and flexibility i.e. sit-and-reach measurements in Japanese. Exercise habits were closely linked to cigarette smoking and the differences flexibility between subjects with and without cigarette smoking were not attenuated even after adjusting for age and exercise habits. We have also reported that aerobic exercise level defined by ventilatory threshold was associated with cigarette smoking in Japanese [6]. Sedentary lifestyle may contribute to the functional decline of subjects and ciga- 
rette smoking may accelerate alterations in several systems and organic functions. Poor trunk flexibility is associated with arterial stiffening [10]. Taken together, a combination of promoting exercise habits and prohibiting cigarette smoking might be considered for improving flexibility in Japanese.

Potential limitations still remain in this study. First, our study was a cross sectional and not a longitudinal study. Second, 4234 men and 9169 women in our study voluntarily underwent measurements: they were therefore more likely to be health-conscious compared with the average person. Third, the difference of changes in flexibility between men and women with aging were noted. Forth, we could not clarify the mechanism of the link between cigarette smoking and flexibility. Smokers often show lower levels of current and past leisure-time physical activity, hormonal disorders and nutritional deficits [11]. However, it seems reasonable to suggest that prohibiting smoking might result in the amelioration of flexibility in some Japanese. To show this, further prospective studies are needed in the Japanese population.

\section{ACKNOWLEDGEMENTS}

This research was supported in part by Research Grants from the Ministry of Health, Labor, and Welfare, Japan. There is no conflict of interest.

\section{REFERENCES}

[1] Ministry of Health, Labor and Welfare, Japan (2012) The national nutrition survey in Japan. http://www.mhlw.go.jp/stf/houdou/2r98520000020qbb-att /2r98520000021c19.pdf

[2] Peto, R. (1994) Smoking and death: The past 40 years and the next 40. British Medical Journal, 209, 937-939. doi:10.1136/bmj.309.6959.937

[3] Ministry of Health, Labor and Welfare, Japan (2012) Exercise and physical activity reference quantity for health promotion 2006. http://www.mhlw.go.jp/shingi/2006/07/dl/s0719-3b.pdf

[4] Committee to Evaluate Diagnostic Standards for Metabolic Syndrome (2005) Definition and the diagnostic standard for metabolic syndrome-Committee to Evaluate Diagnostic Standards for Metabolic Syndrome. Nippon Naika Gakkai Zasshi, 94, 794-809. (in Japanese) doi:10.2169/naika.94.794

[5] Miyatake, N., Miyachi, M., Tabata, I. and Numata, T. (2012) Evaluation of anthropometric parameters and physical fitness in elderly Japanese. Environmental Health and Preventive Medicine, 17, 62-68. doi:10.1007/s12199-011-0220-3

[6] Miyatake, N., Numata, T., Nishii, K., Sakano, N., Suzue, T., Hirao, T., Miyachi, M. and Tabata, I. (2011) Realtion between cigarette smoking and ventilatory threshold in the Japanese. Environmental Health and Preventive Medicine, 16, 185-190. doi:10.1007/s12199-010-0178-6

[7] Conway, T. L. (1989) Behavioral, psychological, and demographic predictors of physical fitness. Psychological Reports, 65, 1123-1135. doi:10.2466/pr0.1989.65.3f.1123

[8] Boyce, R. W., Perko, M. A., Jones, G. R., Hiatt, A. H. and Boone, E. L. (2006) Physical fitness, absenteeism and workers' compensation in smoking and non-smoking police officers. Occupational Medicine (Lond), 56, 353-356. doi:10.1093/occmed $/ \mathrm{kql} 1057$

[9] Ricci, N. A., Francisco, C. O., Rebelatto, M. N. and Rebelatto, J. R. (2011) Influence of history of smoking on the physical capacity of older people. Archieves of Gerontology and Geriatrics, 52, 79-83. doi:10.1016/j.archger.2010.02.004

[10] Yamamoto, K., Kawano, H., Gando, Y., Iemitsu, M., Murakami, H., Sanada, K., Tanimoto, M., Ohmori, Y., Higuchi, M., Tabata, I. and Miyachi, M. (2009) Poor trunk flexibility is associated with arterial stiffening. American Journal of Physiology-Heart and Circulatory Physiology, 297, H1314-H1318. doi:10.1152/ajpheart.00061.2009

[11] Szulc, P., Duboeuf, F., Marchand, F. and Delmas, P. D. (2004) Hormonal and lifestyle determinants of appendiclar skeletal muscle mass in men: The MINOS study. The American Journal of Clinical Nutrition, 80, 496-503. 